\title{
Emotional Memory and Posttraumatic Stress Disorder: A Preliminary Neuropsychological Study in Female Victims of Domestic Violence
}

\author{
Su-Ying Chung ${ }^{1}$, Shu-Hui Tang ${ }^{1}$, Jia-Pei Shie ${ }^{2}$, Kuan-Yi Tsai ${ }^{3}$ and Frank Huang-Chih Chou $^{2,4^{*}}$ \\ ${ }^{1}$ Department of Clinical Psychology, Municipal Kaohsiung Kai-Syuan Psychiatric Hospital, Kaohsiung City, Taiwan \\ ${ }^{2}$ Department of Community Psychiatry, Municipal Kaohsiung Kai-Syuan Psychiatric Hospital, Kaohsiung City, Taiwan \\ ${ }^{3}$ Department of Nursing, Meiho University, Ping-Tong County, Taiwan \\ ${ }^{4}$ Graduate Institute of Health Care, Meiho University, Ping-Tong County, Taiwan
}

*Corresponding author: Frank Huang-Chih Chou, Department of Community Psychiatry, Municipal Kaohsiung Kai-Syuan Psychiatric Hospital 130, Kai-Syuan 2nd Rd, Lingya district, Kaohsiung city, Taiwan ;Tel: 886-7-7513171-2232; Fax: 886-7-5373299; E-mail: f50911.tw@yahoo.com

Received Date: July 11, 2014, Accepted Date: September 23, 2014, Published Date: September 30, 2014

Copyright: (c) 2014, Frank Huang-Chih Chou, et al., This is an open-access article distributed under the terms of the Creative Commons Attribution License, which permits unrestricted use, distribution, and reproduction in any medium, provided the original author and source are credited.

\begin{abstract}
Objectives: The current study was designed to examine the features of emotional memory that are associated with posttraumatic stress disorder and to investigate whether emotional memory and neuropsychological function predict the severity of PTSD symptoms.

Method: Forty-five domestic violence victims were recruited and separated into the PTSD and N-PTSD groups, and 31 healthy volunteers were recruited as the normal control group. All participants filled out self-report instruments and underwent neuropsychological testing as well as an unexpected memory task (emotional memory questionnaire, EMQ) after watching a film on domestic violence. The questionnaire evaluated the participants' memory of the central aspects of the film (EMQ-C) and the peripheral aspects of the film (EMQ-P).

Results: The PTSD group scored lower on the EMQ-C, whereas there were no significant differences for the EMQ-P or neuropsychological measures among the three groups. Additionally, the Modified Card Sorting Test (MCST), category fluency, Verbal Paired Associates and EMQ-C predicted the PTSD symptoms.
\end{abstract}

Conclusions: Both the index of the emotional memory and the perseverative error of MCST are powerful predictors of the severity levels of PTSD symptoms.

\section{Keywords}

Posttraumatic Stress Disorder (PTSD); Neuropsychological function; Domestic violence; Emotional memory

\section{Introduction}

According to the DSM-IV (American Psychiatric Association, 1994), the diagnosis of posttraumatic stress disorder (PTSD) requires a recognized stressor to which a person has been personally exposed or witnessed a traumatic stressor (criteria A). Therefore, Breslau [1] estimated that approximately $90 \%$ of people meet criteria A in their lifetimes. However, only 25-30\% of people then develop PTSD [2-3]. Specifically, previous studies showed that for earthquake trauma [4] or interpersonal violence [5], the rates of survivors with PTSD gradually decreases during the time since the traumatic events. This finding indicates that exposure to a traumatic event is insufficient for developing PTSD and that other individual vulnerability or predisposing factors may contribute to the development and maintenance of PTSD.

PTSD is considered a disorder of emotional memory that involves brain function abnormalities related to fear conditioning, fear memory extinction, involuntary retrieval (flashbacks and intrusions) and context-independent fear [6-10]. Numerous neuroimaging studies have reported diminished activation in the hippocampus in PTSD
[11-13] or significant hippocampal volume reduction in PTSD patients [14-15]. Similarly, the neurocircuitry models of PTSD posit that both hippocampal dysfunction and amygdala hyperactivity are related to the performance of emotional memory in PTSD $[8,16]$. If the hippocampus is not fully functional and does not form conscious emotional memories during a traumatic situation, it will form unconscious emotional memories that are supported by the amygdala [17]. Accordingly, hippocampal volume reduction and activity dysfunction may contribute to the etiology and maintenance of PTSD [18-19].

Although the presence of hippocampal dysfunction is a robust finding in neurobiological studies of PTSD, it is unclear whether the episodic memory for emotional events in PTSD is deficient or enhanced. Based on clinical observations, some veterans with PTSD had amnesia specific to past war experiences, e.g., forgetting their names or certain events in the war [20]. Tromp, Koss, Figueredo, and Tharan [21] found that compared with other unpleasant memories, rape memories are less clear and vivid, contain a less meaningful order, and are not as well remembered. According to van der Kolk and Fisler [22], traumatic memories are initially stored as sensory states due to failures of the hippocampal-based memory system. Therefore, speechlessness and amnesia for traumatic events may last for hours, weeks, or years. Consequently, it is often difficult to assess memory 
Citation: Chung SY, Tang SH, Shie JP, Tsai KY, Huang-Chih Chou F (2014) Emotional Memory and Posttraumatic Stress Disorder: A Preliminary Neuropsychological Study in Female Victims of Domestic Violence. J Psychiatry 17: 1000148. doi: $10.4172 / 2378-5756.1000148$

Page 2 of 9

loss for events using interviews and self-report measures in victims who suffer from traumatic events [23-24].

Conversely, several studies, including pictures simulating car accidents [25], pictures of shootings [26], slides depicting a boy who died in an accident [27], and retrospective self-report, such as verbal accounts of traumatic memories solicited from the subjects (e.g., [28]), reported that emotional stress may lead to a highly restricted narrowing of attention to central details of a situation, resulting in memory for central details being better than memory for peripheral information. This phenomenon was therefore described as tunnel memory [29]. Rubin, Berntsen, and Bohni [30] argued that C3 (the inability to recall an important aspect of the trauma), one of the PTSD symptoms, often has the lowest factor loading because it is more likely to be an outlier from other PTSD symptoms. Moreover, the C3 symptom also contradicts the notion of tunnel memory.

Several explanations might resolve these inconsistent observations. First, it is questionable whether the findings of memory distortions in normal subjects can provide a meaningful understanding of emotional memory in PTSD because there is little similarity between exposure to a simulated trauma event in the laboratory and the experience of real trauma [22]. Second, the notion of tunnel memory may support the theory of an inverted U-shape relationship between arousal and memory if the arousal level is moderate [31]. However, hippocampal functions are expected to be impaired or inhibited at high levels of stress [19]. As such, very high levels of stress may also impair the accuracy of eyewitness memory [32]. Third, if non-clinical subjects in retrospective studies only report an irritable mood while recalling a traumatic memory but do not have PTSD core symptoms, their memory of the shocking event may not resemble that of PTSD victims. Moreover, the subjective feeling of remembering emotional information well does not guarantee accurate memory [33]. Fourth, research designs would improve if the memories of central and peripheral details are compared between participants with high- and low-PTSD symptom levels. Then, high-PTSD participants should have better memory for central details compared with low-PTSD participants. However, previous studies have not provided evidence for this ([34] for a review).

In this regard, the goals of the current study are to examine the memory function in a sample of female victims suffering from domestic violence. As reported by a multi-country study, the lifetime prevalence rate for women of victimization from intimate partner violence is between $15 \%$ and $71 \%$ [35], and approximately $31 \%$ to $84 \%$ of women who are the victims of intimate partner violence have PTSD [36]. In Taiwan, approximately $15 \%$ of women have experienced domestic violence [37], and $94 \%$ of women who were abused by an intimate partner within the past year met the criteria for PTSD [38]. These findings indicate that domestic violence is a potent risk factor for developing PTSD.

As reviewed by Holmes, Brewin and Hennessy [39], the trauma film paradigm provides a prospective experimental tool for investigating analogue peri-traumatic processing. The impact of the films (usually intrusive thoughts) is measured using a daily diary for one week. The current study assumed that a film depicting domestic violence might simulate trauma experiences for female victims and that there could be an analogous situation in which the response to trauma could be studied in the laboratory. Therefore, we modified the method of the trauma film paradigm so that subjects would be evaluated with an emotional memory test for the film instead of measuring the frequency of intrusive thoughts.
We hypothesized that the PTSD group would show poorer memory for the central details of the trauma-related plots compared with the trauma-exposed N-PTSD group (severity level of symptoms did not meet PTSD criteria) and the normal control group. Additionally, to clarify the psychological components of the emotional memory test, the current study examined the relationship between the emotional memory test, standard neuropsychological tests, and trauma-related symptoms. Finally, we investigated whether emotional memory, neuropsychological function, or both were sensitive to the PTSD diagnosis and whether these factors predict the severity of PTSD symptoms.

\section{Method}

\section{Participants}

Participants were recruited from the Kaohsiung City Government Center for Domestic Violence Prevention using an advertisement or were contacted through the Kai-Suan Psychiatric Hospital, Taiwan. The inclusion criteria were that participants (1) had graduated from at least middle school and received elementary and middle school education in Taiwan; (2) were between 18 and 55 years old; and (3) had previous experience with a domestic violence injury. The exclusion criteria included (1) the presence of a medical or organic disease in the central nervous system (CNS; e.g., epilepsy, a tumor or serious brain injury); (2) a history or the presence of psychiatric disorders, with the exception of PTSD, depressive disorder, and anxiety disorder; and (3) an alcohol/substance dependence or abuse in the preceding 12 months.

Forty-five female victims of domestic violence and thirty-one healthy female volunteers participated in this study. All of the female victims had left their perpetrators at least one month prior to joining the study (range: 1-156 months). Additionally, all of the participants were assessed by a clinical interview with a certified psychiatrist or a clinical psychologist to disqualify psychiatric disorders and evaluate potential comorbid disorders. Diagnoses were obtained through the Taiwanese version of the Mini International Neuropsychiatric Interview [40].

Female victims were divided into two groups, the PTSD and NPTSD groups, based on their responses to the Chinese version of the Davidson Trauma Scale (DTS-C). This scale was adapted from the Davidson Trauma Scale (DTS; [41]) and comprised a validated, 17item, self-rated scale of the frequency and severity of PTSD symptoms as defined by the DSM-IV-R. Using this test, the 3 clusters of symptoms (Intrusive, Avoidance/ Numbing, and Hyperarousal) can also be scored separately. The DTS-C was translated from the DTS and has shown good internal consistency (Cronbach's $\alpha=0.97$ ) and testretest reliability $(r=0.88)$. Concurrent validity was obtained against clinical diagnostic interviews, with a diagnostic accuracy of 0.85 and a DTS-C score of 44, based on the study of the Chi-Chi Earthquake [42].

Of the 45 domestic violence victims in this study, 28 scored 44 or higher on the DTS-C and were classified into the PTSD group; 17 were classified in the N-PTSD group; and 30 were healthy volunteers without psychiatric disorders, neurological diseases, or traumatic experiences recruited as the normal control group (NC). The average number of months since leaving the abusive partner in the PTSD group was $39.39(\mathrm{SD}=51.73)$, whereas this average in the Non-PTSD group was $45.75(\mathrm{SD}=53.38)$. 
Citation: Chung SY, Tang SH, Shie JP, Tsai KY, Huang-Chih Chou F (2014) Emotional Memory and Posttraumatic Stress Disorder: A Preliminary Neuropsychological Study in Female Victims of Domestic Violence. J Psychiatry 17: 1000148. doi: $10.4172 / 2378-5756.1000148$

Page 3 of 9

\section{Procedure}

The study protocol was reviewed and approved by the Institutional Review Board of the Kai-Suan Psychiatric Hospital. Before they were assessed, the participants were fully informed about the study's aims, examination content, and procedure. After each participant agreed and completed the informed consent forms, the researchers initiated the one-on-one individual assessment. All participants were assessed using a structured interview to evaluate their medical history, life stress and traumatic experience. After recruitment, the psychiatrists would prescribe psychiatric drugs to participants according to their mental conditions. Some participants agreed to undergo psychotherapy.

\section{Measures}

Estimated general intellectual potential: We estimated IQ with a prorated combination of the following two WAIS-III [43] subtests: Vocabulary and Matrix Reasoning. This combination of subtests is robustly related to the full-scale IQ test [44].

Learning and memory measures: (a) The Verbal Paired Associates subtest of the Wechsler Memory Scale [45] involving immediate (VPA-I) and delayed recall (VPA-II) and (b) the Rey Auditory Verbal Learning Test (RAVLT; $[46,47]$ ) involving total learning, immediate recall following the interference trial, and 30-minute delayed recall.

Executive function: We used (a) the Modified Card Sorting Test (MCST; [48]) and (b) Category Fluency (i.e.,"fruits, four-legged animals, and vegetables").

Attention and working memory: The WAIS-III Digit Span subtest and the first trial of RAVLT were used.

Psychomotor Speed: Part A of the Trial Making Test (TMT-A; [46]) was used.

Trauma-related symptomatology and psychiatric comorbidity: We used (a) the DTS-C [42], (c) the Beck Depression Inventory [49], and (d) the Beck Anxiety Inventory [50].

Emotional memory questionnaire: For the pilot study, the study used a domestic violence film produced by the Ministry of Interior. The film, entitled 'Family,' is eight minutes long and primarily describes a story of physical conflict among families. The film contains five scenes; the first and fifth scenes depict a husband (father) violently and physically attacking his wife (mother), causing severe conflict with his son while his daughter withdraws to her bedroom in fear and horror. The story in the remaining three scenes is less emotionally arousing and depicts the son complaining to his classmate about his father's violence; the daughter painting the face of a crying girl in school; and a short talk between the father and a neighbor.

Initially, 35 fill-in-the-blank questions regarding the film were developed, and 25 graduate and undergraduate students completed the memory test after viewing the film. Based on their answers, a 20 -item questionnaire (emotional memory questionnaire, EMQ) was developed that consisted of ten questions that were directly related to the violence plot (central aspects, EMQ-C) and ten other questions related to the non-violent plot (peripheral aspects, EMQ-P). Specifically, among the 20 fill-in-the-blank questions, the first and last 10 questions included five questions from the EMQ-C and five questions from the EMQ-P, respectively.
There were four sub-scores in total, which included immediate recall of the central aspects of the film (EMQ1-C), immediate recall of the peripheral aspects of the film (EMQ1-P), delayed recall of the central aspects of the film (EMQ2-C), and delayed recall of the peripheral aspects of the film (EMQ2-P). There were 31 healthy women (age: $\mathrm{M}=29.58, \mathrm{SD}=9.73$; education: $\mathrm{M}=15.26, \mathrm{SD}=1.21$ ) in the pilot study who were not participants in this current study. Our results revealed that the split-half reliability (the first 10 and the latter 10 questions) of the EMQ1 (immediate recall) and EMQ2 (delayed recall) were 0.98 and 0.92 , respectively. Paired $t$ tests indicated that neither the difference between the EMQ1-C and EMQ1-P nor the difference between the EMQ2-C and EMQ2-P were significantly different $(\mathrm{t}(30)$, $\mathrm{p}>0.10$ ), indicating that the difficulty level was similar between the EMQ-C and EMQ-P.

Procedure: The procedure for the experiment was as follows: All subjects underwent psychophysiological measures while watching the film. The Biograph Infiniti software using the multimodality systems of Thought Technology was used in this study. Five measures, including the blood volume pulse (BVP), electromyography (EMG), respiration rate, finger temperature, and galvanic skin response (GSR), were collected. The psychophysiological reactivity data were computed with five physiological measures for both the baseline and film periods. Analyses were conducted using change scores that were calculated by subtracting the period average of baseline from the average of the first and the fifth scene period (the central aspects of the film). After watching the film, the participants were asked to rate the subjective distress caused by the film (0-100) and were advised to relax for three minutes. They were then given a surprise memory test (immediate recall of the EMQ). After finishing the questionnaire, the participants continued to perform an irrelevant filler task and then filled out the same EMQ (delayed recall of the EMQ) 30 minutes later.

\section{Results}

\section{Characteristics of the study participants}

To assess the extent to which the groups were demographically matched, we conducted ANOVAs comparing the age, education, and estimated IQ among the three groups. As Table 1 shows, the groups did not differ in terms of their age, education, WAIS-IV Vocabulary subtest, and estimated IQ. Additionally, there were significant differences among the groups on the BDI-II $(\mathrm{F}=72.001, \mathrm{p}<0.001)$ and the BAI $(\mathrm{F}=63.935, \mathrm{p}<0.001)$. A significant difference was also noted on the DTS-C between the PTSD and N-PTSD groups $(\mathrm{F}=58.128, \mathrm{p}<0.001$.

\section{Memory of the trauma film and neuropsychological function}

The mean and standard deviations for every index of the EMQ and neuropsychological test were separately calculated for each group (Table 2). Multivariate analysis of variance (MANOVA) was used to examine group differences in the EMQ. There was a significant main effect of the group (Wilks' $\Lambda=0.787, \mathrm{~F}=2.199, \mathrm{p}<0.05$ ), and the univariate analyses regarding EMQ1-C $(\mathrm{F}=6.899, \mathrm{p}<0.01)$ and EMQ2$\mathrm{C}(\mathrm{F}=6.747, \mathrm{p}<0.01)$ were significant. Post-hoc Tukey tests indicated that the PTSD group showed significantly poorer recall of the EMQ1-C and EMQ2-C than the N-PTSD group $(\mathrm{p}<0.01)$. Additionally, the PTSD group showed significantly poorer recall of the EMQ2-C than the NC group $(\mathrm{p}<0.05)$. Furthermore, ANOVA revealed that there were significant differences between groups regarding the BVP $(\mathrm{F}=4.827$, $\mathrm{p}=0.011$ ). Post-hoc Tukey tests indicated that the 
Citation: Chung SY, Tang SH, Shie JP, Tsai KY, Huang-Chih Chou F (2014) Emotional Memory and Posttraumatic Stress Disorder: A Preliminary Neuropsychological Study in Female Victims of Domestic Violence. J Psychiatry 17: 1000148. doi: $10.4172 / 2378-5756.1000148$

Page 4 of 9

PTSD group showed significant BVP change compared with the NC group ( $\mathrm{p}=0.012)$, and the PTSD group exhibited a marginally significant BVP change compared with the N-PTSD group $(\mathrm{p}=0.072)$.

\begin{tabular}{|c|c|c|c|c|c|}
\hline & $\begin{array}{l}\text { (1) PTSD } \\
\mathrm{N}=28\end{array}$ & $\begin{array}{l}\text { (2) N-PTSD } \\
\mathrm{N}=17\end{array}$ & $\begin{array}{l}\text { (3) NC } \\
N=30\end{array}$ & $\mathbf{F}$ & Tukey \\
\hline Age & $36.68(9.14)$ & $42.00(12.12)$ & $37.17(11.56)$ & 1.448 & \\
\hline Education & $13.64(2.30)$ & $13.35(1.84)$ & $14.20(1.61)$ & 1.180 & \\
\hline $\mathrm{IQ}$ & $100.55(11.55)$ & $100.79(9.75)$ & $100.59(12.74)$ & 0.002 & \\
\hline WAIS-Va & $9.93(1.81)$ & $9.71(2.02)$ & $9.57(2.16)$ & 0.873 & \\
\hline BDI-II & $34.00(15.57)$ & $8.00(4.51)$ & $4.53(3.61)$ & $70.042^{c}$ & $1-2^{c}, 1-3^{c}$ \\
\hline $\mathrm{BAl}$ & $27.36(13.20)$ & $8.65(6.06)$ & $2.53(2.29)$ & $62.037^{c}$ & $1-2^{c}, 1-3^{c}$ \\
\hline DTS-C & $86.89(25.31)$ & $25.65(10.75)$ & & $58.128^{c}$ & \\
\hline
\end{tabular}

Table 1: Mean and standard deviation of the participants' demographic and clinical characteristics ,IQ: Estimated FSIQ; WAIS-Va: WAIS-IV Vocabulary subtest; BDI-II: Beck Depression Inventory II; BAI: Beck Anxiety Inventory; and DTS-C: Chinese version of the Davidson Trauma Scale, a: $\mathrm{p}<0.05 ; \mathrm{b}: \mathrm{p}<0.01 ; \mathrm{c}: \mathrm{p}<0.001$

\begin{tabular}{|c|c|c|c|}
\hline & $\begin{array}{l}\text { PTSD } \\
\mathrm{N}=28\end{array}$ & $\begin{array}{l}\mathrm{N}-\mathrm{PTSD} \\
\mathrm{N}=17\end{array}$ & $\begin{array}{l}\mathrm{NC} \\
\mathrm{N}=30\end{array}$ \\
\hline \multicolumn{4}{|l|}{ Emotion Memory } \\
\hline EMQ1-P & $7.75(1.58)$ & $7.94(1.82)$ & $8.20(1.56)$ \\
\hline EMQ1-C & $6.39(1.79)$ & $8.24(1.60)$ & $7.50(1.61)$ \\
\hline EMQ2-P & $7.79(1.60)$ & $8.00(1.66)$ & $8.13(1.61)$ \\
\hline EMQ2-C & $6.57(1.75)$ & $8.18(1.43)$ & $7.77(1.48)$ \\
\hline Subjective Distress & $71.85(25.01)$ & $65.29(30.64)$ & $42.50(26.15)$ \\
\hline BVP change & $1.97(3.50)$ & $-0.47(3.83)$ & $-0.77(3.35)$ \\
\hline \multicolumn{4}{|c|}{ Neuropsychological Function } \\
\hline VPA-I & $8.93(2.85)$ & $9.71(2.23)$ & $9.37(2.74)$ \\
\hline VPA-II & $9.18(3.40)$ & $11.00(2.40)$ & $9.33(2.81)$ \\
\hline RAVLT-1 & $5.46(2.20)$ & $6.06(2.44)$ & $6.80(2.14)$ \\
\hline RAVLT-T & $50.21(10.43)$ & $53.06(10.27)$ & $55.03(7.07)$ \\
\hline RAVLT-D & $10.39(3.79)$ & $11.41(4.12)$ & $12.00(2.63)$ \\
\hline MCST-C & $4.29(2.34)$ & $5.06(2.51)$ & $5.10(1.77)$ \\
\hline MCST-PE & $4.89(5.88)$ & $1.47(2.18)$ & $3.39(4.65)$ \\
\hline $\mathrm{CF}$ & $40.14(9.14)$ & $45.24(7.52)$ & $43.23(8.89)$ \\
\hline DS & $21.36(4.64)$ & $21.88(3.35)$ & $21.73(3.66)$ \\
\hline TMT-A & $39.57(14.78)$ & $31.82(12.69)$ & $31.50(7.06)$ \\
\hline
\end{tabular}

Table 2: Performance of the groups for the EMQ and neuropsychological tests (showing mean scores with the standard deviation), EMQ1-P: peripheral part of immediate recall, EMQ1-C: central part of immediate recall, EMQ2-P: peripheral part of delayed recall, EMQ2-C: central part of delayed recall, VPA-I: Verbal Paired Associates Immediate Recall, VPA-II: Verbal Paired Associates Delayed Recall, RAVLT-1: First Trial of 
Citation: Chung SY, Tang SH, Shie JP, Tsai KY, Huang-Chih Chou F (2014) Emotional Memory and Posttraumatic Stress Disorder: A Preliminary Neuropsychological Study in Female Victims of Domestic Violence. J Psychiatry 17: 1000148. doi: $10.4172 / 2378-5756.1000148$

Page 5 of 9

Rey Auditory Verbal Learning Test, RAVLT-T: Total Scores of Rey Auditory Verbal Learning Test, RAVLT-D: Rey Auditory Verbal Learning Test Delayed Recall, MCST-PEModified Card Sorting Test -Number of Perseverative Error, MCST-CModified Card Sorting Test-Number of Category, CF: Category Fluency, DS: Digit Span, and TMT-A: Trial Making Test Part A

Additionally, there were significant differences on the index of Subjective Distress $(\mathrm{F}=9.352, \mathrm{p}<0.000)$ between the three groups. Posthoc Tukey tests indicated that the PTSD $(\mathrm{p}<0.000)$ and N-PTSD $(\mathrm{p}<$ 0.05 ) groups showed significant subjective distress with respect to the trauma film relative to the $\mathrm{NC}$ group.

Similarly, the MANOVA was used to examine group differences in the neuropsychological tests. A significant overall main effect of the group (Wilks' $\Lambda=0.512, \mathrm{~F}=1.683, \mathrm{p}<0.05$ ) was noted, whereas the results of the univariate analyses on the MCST-PE $(\mathrm{F}=3.466, \mathrm{p}<0.05)$ were significantly different. Post-hoc Tukey tests indicated that the PTSD group showed higher preservative errors than the N-PTSD group $(\mathrm{p}<0.01)$, while there were no significant differences between the PTSD and NC groups.

\section{Predictors of posttraumatic stress symptoms}

A Pearson correlation analysis was used to clarify the relationship between the neuropsychological tests and PTSD symptoms in female victims. According to the correlation matrix results, VPA-I was significantly correlated with re-experiencing $(\mathrm{r}=-0.42, \mathrm{p}<0.01)$ and overall PTSD severity $(\mathrm{r}=-0.30, \mathrm{p}<0.05)$, whereas VPA-II was significantly correlated with re-experiencing $(\mathrm{r}=-0.41, \mathrm{p}<0.01)$, hyperarousal $(r=-0.31, p<0.05)$, and overall PTSD severity $(r=-0.31, p$ $<0.05)$. The MCST-PE was significantly correlated with re-experiencing $(\mathrm{r}=0.30, \mathrm{p}<0.05)$, avoidance $(\mathrm{r}=0.43, \mathrm{p}<0.01)$, hyperarousal $(\mathrm{r}=0.38, \mathrm{p}<$ $0.01)$, and the overall PTSD severity $(\mathrm{r}=0.41, \mathrm{p}<0.01)$. The category fluency was significantly correlated with re-experiencing $(\mathrm{r}=-0.42, \mathrm{p}<$ $0.01)$, avoidance $(\mathrm{r}=-0.32, \mathrm{p}<0.05)$, hyperarousal $(\mathrm{r}=-0.32, \mathrm{p}<0.05)$, and the overall PTSD severity $(\mathrm{r}=-0.37, \mathrm{p}<0.05)$.

With respect to the relationship between the EMQ, neuropsychological tests, and trauma-related symptoms, the EMQ1-C was significantly correlated with BDI-II $(r=0.45, \mathrm{p}<0.01)$, BAI $(\mathrm{r}=-0.43$, $\mathrm{p}<0.01)$, re-experiencing $(\mathrm{r}=-0.51, \mathrm{p}<0.001)$, avoidance $(\mathrm{r}=0.37, \mathrm{p}<.05)$, hyperarousal $(\mathrm{r}=-0.38, \mathrm{p}=0.01)$, the overall PTSD severity $(\mathrm{r}=-0.45$, $\mathrm{p}<0.01)$, VPA-II $(\mathrm{r}=0.32, \mathrm{p}<0.05)$, TMT-A $(\mathrm{r}=-0.49, \mathrm{p}=0.001)$, and the category fluency $(\mathrm{r}=0.36, \mathrm{p}<0.05)$; and the correlation between the EMQ1-C and delayed recall of RAVLT $(r=0.28, p<0.07)$ was marginally significant. Additionally, EMQ2-C was also significantly correlated with BDI-II $(\mathrm{r}=-0.45, \mathrm{p}<0.01)$, BAI $(\mathrm{r}=-0.43, \mathrm{p}<0.01)$, re-experiencing $(\mathrm{r}=-0.48, \mathrm{p}=0.001)$, avoidance $(\mathrm{r}=-0.38, \mathrm{p}<0.05)$, hyperarousal $(\mathrm{r}=-0.34$, $\mathrm{p}<0.05)$, overall PTSD severity $(\mathrm{r}=-0.43, \mathrm{p}<0.01)$ and TMT-A $(\mathrm{r}=-0.35$, $\mathrm{p}<0.05)$; the correlation between EMQ2-C and VPA-II $(r=0.28, \mathrm{p}<0.07)$ was marginally significant. However, the EMQ1-P was significantly correlated with delayed recall of RAVLT $(r=0.38, p<0.05)$, TMT-A $(\mathrm{r}=-0.44, \mathrm{p}<0.01)$, and category fluency $(\mathrm{r}=0.37, \mathrm{p}<0.05)$, and the EMQ2-P was correlated with delayed recall of RAVLT $(r=0.32$, $\mathrm{p}<0.05)$, TMT-A $(\mathrm{r}=-0.38, \mathrm{p}<0.05)$, category fluency $(\mathrm{r}=0.34, \mathrm{p}<0.05)$, and EMQ1-C $(r=0.31, \mathrm{p}<0.05)$.

The impacts of neuropsychological functions and emotional memory on the PTSD symptoms were evaluated using simultaneous regression analysis with an Enter entry criterion of $\mathrm{p}<0.05$. The predictor included VPA-I, MCST-PE, category fluency, and EMQ2-C because these indexes showed high correlations with PTSD symptoms.

\begin{tabular}{|c|c|c|c|c|c|c|}
\hline Predicting Variables & B & SE & $\beta$ & $t$ & $\mathbf{R}^{2}$ & Adj $R^{2}$ \\
\hline Predicting Re-experience & & & & & $\begin{array}{l}0.47 \\
3\end{array}$ & 0.420 \\
\hline VPA-I & $\begin{array}{l}-0.65 \\
0\end{array}$ & 0.639 & $\begin{array}{l}-0.15 \\
3\end{array}$ & $-1.018^{a}$ & & \\
\hline MCST-PE & 0.710 & 0.261 & 0.321 & $2.725^{\mathrm{d}}$ & & \\
\hline $\mathrm{CF}$ & $\begin{array}{l}-0.29 \\
4\end{array}$ & 0.189 & $\begin{array}{l}-0.23 \\
1\end{array}$ & $-1.557^{a}$ & & \\
\hline EMQ2-C & $\begin{array}{l}-2.77 \\
7\end{array}$ & 0.738 & $\begin{array}{l}-0.44 \\
5\end{array}$ & $-3.761^{e}$ & & \\
\hline Predicting Avoidance & & & & & $\begin{array}{l}0.42 \\
8\end{array}$ & 0.371 \\
\hline VPA-I & 0.997 & 0.970 & 0.160 & $1.028^{a}$ & & \\
\hline MCST-PE & 1.566 & 0.396 & 0.485 & $3.956^{\mathrm{e}}$ & & \\
\hline $\mathrm{CF}$ & $\begin{array}{l}-0.61 \\
1\end{array}$ & 0.287 & $\begin{array}{l}-0.32 \\
9\end{array}$ & $-2.128^{c}$ & & \\
\hline EMQ2-C & $\begin{array}{l}-3.54 \\
7\end{array}$ & 1.121 & $\begin{array}{l}-0.39 \\
0\end{array}$ & $-3.163^{d}$ & & \\
\hline Predicting Hyperarousal & & & & & $\begin{array}{l}0.35 \\
1\end{array}$ & 0.286 \\
\hline VPA-I & 0.059 & 0.741 & 0.013 & $0.080^{a}$ & & \\
\hline MCST-PE & 0.965 & 0.302 & 0.417 & $3.194^{d}$ & & \\
\hline $\mathrm{CF}$ & $\begin{array}{l}-0.33 \\
2\end{array}$ & 0.219 & $\begin{array}{l}-0.25 \\
0\end{array}$ & $-1.516^{a}$ & & \\
\hline EMQ2-C & $\begin{array}{l}-2.20 \\
6\end{array}$ & 0.856 & $\begin{array}{l}-0.33 \\
8\end{array}$ & $-2.576^{c}$ & & \\
\hline $\begin{array}{l}\text { Predicting the PTSD } \\
\text { severity }\end{array}$ & & & & & $\begin{array}{l}0.46 \\
5\end{array}$ & 0.412 \\
\hline VPA-I & 0.405 & 2.092 & 0.029 & $0.194^{a}$ & & \\
\hline MCST-PE & 3.242 & 0.854 & 0.450 & $3.796^{\mathrm{e}}$ & & \\
\hline $\mathrm{CF}$ & $\begin{array}{l}-1.23 \\
8\end{array}$ & 0.620 & $\begin{array}{l}-0.29 \\
9\end{array}$ & $-1.998^{b}$ & & \\
\hline EMQ2-C & $\begin{array}{l}-8.52 \\
9\end{array}$ & 2.419 & $\begin{array}{l}-0.42 \\
0\end{array}$ & $-3.526^{\mathrm{e}}$ & & \\
\hline
\end{tabular}

Table 3: Simultaneous Multiple Regression Analysis Predicting Reexperiencing, Avoidance/Numbing, Hyperarousal, and the overall PTSD Severity, VPA-I: Verbal Paired Associates immediate recall, MCST-PE: Modified Card Sorting Test - number of preservative errors, CF: Category Fluency, and EMQ2-C: central part of delayed recall, a: $\mathrm{P}>0.10$; b: $\mathrm{P} 00.10$; c: $\mathrm{P}<0.05$; $\mathrm{d}: \mathrm{P}<0.01$, and e: $\mathrm{P} \leqq 0.001$. 
Citation: Chung SY, Tang SH, Shie JP, Tsai KY, Huang-Chih Chou F (2014) Emotional Memory and Posttraumatic Stress Disorder: A Preliminary Neuropsychological Study in Female Victims of Domestic Violence. J Psychiatry 17: 1000148. doi: $10.4172 / 2378-5756.1000148$

Page 6 of 9

As shown in Table 3, the 4-predictor model explained $47 \%$ of the variance in the severity of intrusive re-experiencing $(\mathrm{F}[4,40]=8.967$; $\mathrm{p}<0.000), 43 \%$ of the variance in the severity of avoidance ( $[4,40]$ $=7.488 ; \mathrm{p}<0.000), 35 \%$ of the variance in the severity of hyperarousal symptoms $(\mathrm{F}[4,40]=5.414 ; \mathrm{p}=0.001)$, and $47 \%$ of the variance in the overall severity of PTSD symptoms $(\mathrm{F}[4,40]=8.704 ; \mathrm{p}<0.000)$. In particular, it is worth noting that the indexes of MCST-PE and EMQ2$\mathrm{C}$ were the most powerful predictors for the severity of PTSD symptoms.

\section{Discussion}

During the past two decades, studies have used neuropsychological testing to elucidate the brain-behavior relationships in PTSD [51]. Accordingly, numerous neuropsychological studies have demonstrated verbal declarative memory deficits in both combat and non-combat PTSD (e.g., [52-54]). Several studies have also reported that PTSD is associated with executive dysfunction (e.g., [55-57]). This evidence suggests that neuropsychological deficits in PTSD involve dysfunction in the arousal systems and frontal-limbic neural circuits [58,59].

However, not all neuropsychological studies have noted memory impairments in PTSD; some studies have found no evidence of memory dysfunction related to PTSD (e.g., $[57,60,61]$ ) or any evidence that the group differences on the WAIS Vocabulary subtest could account for the group differences on the memory tests [62]. Possible explanations for this discrepancy include the following: (1) the neuropsychological studies associated with PTSD may be compromised by other psychotic or neurological disorders, substance abuse, and poor intelligence, and (2) a robust association between PTSD and verbal memory impairment perhaps reflects a motivational problem rather than a specific neuropsychological deficit [58]. Therefore, it is worth assessing whether the associations between PTSD and verbal memory deficits are related to the trauma event.

Consistent with several studies [57,60,63], after excluding conditions involving CNS diseases, psychotic disorders, substance abuse, and low intelligence, the current study failed to find group-level deficits on the standard neuropsychological measures. On the contrary, the results of the EMQ indicated that difficulty in recollecting the central details related to the violent story is significantly higher in the PTSD group than in the N-PTSD and NC groups, whereas no remarkable differences in memory for peripheral details were noted among the PTSD, N-PTSD and NC groups. These findings show that with higher numbers of PTSD symptoms, subjects have increasing difficulty in recalling the central details of the violent story. Therefore, these results are consistent with an fMRI study that found that increased PTSD symptom severity predicted a reduced performance in an emotional memory test [64] while failing to support the notion of tunnel memory. More specifically, while the PTSD group participants only showed worse memory for the central details, their memories for the peripheral details and neutral verbal learning materials were no different from the NC and N-PTSD groups, indicating that the emotional memory deficits in the PTSD group do not resemble the typical amnesic syndrome caused by damage of the medial temporal lobe [65].

In addition to the reported higher levels of subjective distress regarding the trauma film in the PTSD and N-PTSD groups, the PTSD group also showed higher physiological arousal (e.g., heart rate) during the violent plots of the film compared with the NC and $\mathrm{N}$ -
PTSD groups. These results are consistent with the inverted U-shape curve model, which has shown episodic memory decreases with higher physiological arousal [31]. Additionally, these results are consistent with a recent neuroimaging study in which PTSD patients with high levels of arousal had lower hippocampal activity for encoding itemspecific, contextual information for trauma events [19]. Furthermore, the results are congruent with previous studies in which patients with PTSD produce higher heart rate responses to reminders or emotionally arousing stories $[66,67]$, suggesting that a heightened physiological response may reflect fear-related symptoms [68].

It is possible that neuropsychological tests may not be sensitive to a PTSD diagnosis based on the artificial dividing lines between normal and abnormal, but these tests may predict the levels of PTSD symptoms based on a continuous measure of the PTSD symptom severity. Accordingly, the current findings showed that there were high associations among the MCST, category fluency, Verbal Paired Associates test and self-reported PTSD symptoms. Specifically, the index of perseverative errors on the MCST was the strongest predictor of the severity of PTSD symptoms, and the results support the findings of a study on political violence [56] but fail to support a study examining female victims of intimate partner violence in which there were no significant correlations between the PTSD severity and measures of executive function [57]. Executive function is speculated to be a composite term for higher cognitive processes, such as planning, working memory, attention, problem solving, verbal reasoning, inhibition, and mental flexibility [69]. Different instruments may measure different executive functions differently. Therefore, as suggested by the present results, much lower perseverative errors on the MCST may reflect better mental flexibility that may possibly constitute a protective factor for preventing PTSD development.

Finally, there are several implications and limitations in the current results. First, some patients with PTSD might speak out to describe their traumatic events, and these contents seemed to fragment and lack a series of consequences. Some researchers have suggested that these victims would like to avoid recalling traumatic events due to emotional distress such that these victims cannot completely report the traumatic event [70], and female victims in particular seem to have dissociative symptoms and adopt avoidance to cope with traumatic events [71]. Some researchers have shown that whether victims have dissociative symptoms is a major index of PTSD prediction [72,73]. According to the DSM-5 criteria [74] (APA, 2013), the original C3 criteria have been changed to be part of D (D1), which were called negative alterations in cognitions and mood. According to DSM-5, these symptoms are related to dissociative amnesia. We suggest that future emotional memory studies have participants watch traumatic movies and consider the dissociative severities for clarifying the dissociative severities affecting emotional memory.

Second, the victims' reports of subjective distress are not helpful for the PTSD diagnosis, according to our findings. In fact, some researchers have found that there is no significant relationship between the A2 criteria of the DSM-IV-TR (response involves "fear, helplessness, or horror") and a later PTSD diagnosis [75,76]. The diagnostic criteria have been omitted from DSM-5 [74]. However, these victims suffered from traumatic events and complained of emotional distress, which might not have a significant relationship with developing PTSD or the symptom severity. When clinicians evaluate the traumatic severities of victims in the future, they should 
Citation: Chung SY, Tang SH, Shie JP, Tsai KY, Huang-Chih Chou F (2014) Emotional Memory and Posttraumatic Stress Disorder: A Preliminary Neuropsychological Study in Female Victims of Domestic Violence. J Psychiatry 17: 1000148. doi: $10.4172 / 2378-5756.1000148$

Page 7 of 9

avoid incorporating the effects of subjective complaints to avoid evaluation bias.

Third, whether the current results can be applied to other trauma groups is questionable. In addition to the high comorbidity of depression in both men and women, alcohol abuse, brain injury, low intelligence, and other psychiatric disorders have frequently been noted in PTSD studies [77-79]. Additionally, a previous study noted that women suffering from repeated interpersonal trauma had significantly higher levels of PTSD symptoms than did other trauma groups [80]. Care should be taken when applying the current results to other trauma groups.

Fourth, according to Pico-Alfonso [81], 48\% of abused women are still living with their male intimate partners, even after the partners had abused them. Similarly, we found that approximately one of every four female victims did not leave their perpetrators, resulting in ongoing trauma. We excluded these women from the statistical analysis because the perpetrator is both the source of threat and the source of intimacy for these women. Indeed, it has been argued that the traditional PTSD framework is unsuitable for evaluating domestic violence against women because the ongoing nature of abuse renders the term 'post trauma' inaccurate [82]. As observed by Hoffman, Diamond, and Lipsitz [83], if individuals remain exposed to ongoing trauma, traumatic events may become commonplace because these victims suffer constant reminders of the trauma during daily life. Therefore, abused women who remain with their perpetrators could present with different issues compared with women who have left violent relationships because these women may override the fear response and lose their sense of self (see [84] for a review). Therefore, we suggest that further exploration of the ongoing trauma experience is important.

In summary, the current study aimed to clarify the psychopathology of PTSD by integrating both neurocognitive and trauma-relevant tasks. Future studies are needed to more definitively identify the mechanisms of emotional memory in PTSD and to investigate the phenomenon of ongoing trauma in female victims of domestic violence.

\section{Acknowledgements}

This study is supported by funding from the National Science Council research project (NSC 97-2314-B-280-001-MY3) and the KaiSuan Hospital Research Programs (KSPH-2009-05 and KSPH-2010-02).

\section{References}

1. Breslau N (2002) Gender differences in trauma and posttraumatic stress disorder. J Gend Specif Med 5: 34-40.

2. Acierno R, Kilpatrick DG, Resnick HS (1999) Posttraumatic stress disorder in adults relative to criminal victimization: Prevalence, risk factors, and comorbidity. In: Saigh PA, Bremner JD eds. Posttraumatic stress disorder: A comprehensive text. Boston: Allyn and Bacon 44-68.

3. Dohrenwend BP, Turner JB, Turse NA, Adams BG, Koenen KC, et al. (2006) The psychological risks of Vietnam for U.S. veterans: a revisit with new data and methods. Science 313: 979-982.

4. Su CY, Tsai KY, Chou FHC, Ho WW, Liu R, et al. (2010) A three-year follow-up study of the psychosocial predictors of delayed and unresolved post-traumatic stress disorder in Taiwan Chi-Chi earthquake survivors. Psychiatry and Clinical Neurosciences 64: 239-248.
5. Riggs DS, Rothbaum BO, Foa EB (1995) A Prospective Examination of Symptoms of Posttraumatic Stress Disorder in Victims of Nonsexual Assault. Journal of Interpersonal Violence 10: 201.

6. Andrews G, Charney DS, Sirovatka PJ, Regier, DA (2008) Stress-Induced and Fear Circuitry Disorders: Refining the Research Agenda for DSM-V. Arlington: American Psychiatric Pub.

7. Bryant RA, Kemp AH, Felmingham KL, Liddell B, Olivieri G, et al. (2008) Enhanced amygdala and medial prefrontal activation during nonconscious processing of fear in posttraumatic stress disorder: an fMRI study. Hum Brain Mapp 29: 517-523.

8. Shin LM, Handwerger K (2009) Is posttraumatic stress disorder a stressinduced fear circuitry disorder? J Trauma Stress 22: 409-415.

9. Tronel S, Alberini CM (2007) Persistent disruption of a traumatic memory by postretrieval inactivation of glucocorticoid receptors in the amygdala.

10. Biol Psychiatry 62: 33-39.

11. Wolf OT (2008) The influence of stress hormones on emotional memory: relevance for psychopathology. Acta Psychol (Amst) 127: 513-531.

12. Bremner JD, Vythilingam M, Vermetten E, Southwick SM, McGlashan T, et al. (2003) MRI and PET study of deficits in hippocampal structure and function in women with childhood sexual abuse and posttraumatic stress disorder. Am J Psychiatry 160: 924-932.

13. Geuze E, Vermetten E, Ruf M, de Kloet CS, Westenberg HG (2008) Neural correlates of associative learning and memory in veterans with posttraumatic stress disorder. J Psychiatr Res 42: 659-669.

14. Shin LM, McNally RJ, Kosslyn SM, Thompson WL, Rauch SL, et al. (1999) Regional cerebral blood flow during script-driven imagery in childhood sexual abuse-related posttraumatic stress disorder: A positron emission tomographic investigation. American Journal of Psychiatry 156: 575-584.

15. Apfel BA, Ross J, Hlavin J, Meyerhoff DJ, Metzler TJ, et al. (2011) Hippocampal volume differences in Gulf War veterans with current versus lifetime posttraumatic stress disorder symptoms. Biol Psychiatry 69: 541-548.

16. Wignall EL, Dickson JM, Vaughan P, Farrow TF, Wilkinson ID, et al. (2004) Smaller hippocampal volume in patients with recent-onset posttraumatic stress disorder. Biol Psychiatry 56: 832-836.

17. Rauch SL, Shin LM, Phelps EA (2006) Neurocircuitry models of posttraumatic stress disorder and extinction: human neuroimaging research--past, present, and future. Biol Psychiatry 60: 376-382.

18. Ledoux JE, Muller J (1997) Emotional memory and psychopathology. Philos Trans R Soc Lond B Biol Sci 352: 1719-1726.

19. Acheson DT, Gresack JE, Risbrough VB (2012) Hippocampal dysfunction effects on context memory: possible etiology for posttraumatic stress disorder. Neuropharmacology 62: 674-685.

20. Hayes JP, LaBar KS, McCarthy G, Selgrade E, Nasser J, et al. (2011) Reduced hippocampal and amygdala activity predicts memory distortions for trauma reminders in combat-related PTSD. J Psychiatr Res 45: 660-669.

21. Bremner JD, Randall P, Scott TM, Bronen RA, Seibyl JP, et al. (1995) MRI-based measurement of hippocampal volume in patients with combat-related posttraumatic stress disorder. Am J Psychiatry 152: 973-981.

22. Tromp S, Koss MP, Figueredo AJ, Tharan M (1995) Are rape memories different? A comparison of rape, other unpleasant, and pleasant memories among employed women. J Trauma Stress 8: 607-627.

23. van der Kolk BA, Fisler R (1995) Dissociation and the fragmentary nature of traumatic memories: overview and exploratory study. J Trauma Stress 8: 505-525.

24. King DW, Leskin GA, King LA, Weathers FW (1998) Confirmatory factor analysis of the clinician-administered PTSD Scale: Evidence for the dimensionality of posttraumatic stress disorder. Psychological Assessment 10: 90-96.

25. Scher CD, McCreary DR, Asmundson GJ, Resick PA (2008) The structure of post-traumatic stress disorder symptoms in three female 
Citation: Chung SY, Tang SH, Shie JP, Tsai KY, Huang-Chih Chou F (2014) Emotional Memory and Posttraumatic Stress Disorder: A Preliminary Neuropsychological Study in Female Victims of Domestic Violence. J Psychiatry 17: 1000148. doi: $10.4172 / 2378-5756.1000148$

Page 8 of 9

trauma samples: a comparison of interview and self-report measures. J Anxiety Disord 22: 1137-1145.

26. Christianson SA, Loftus EF, Hoffman H, Loftus GR (1991) Eye fixations and memory for emotional events. J Exp Psychol Learn Mem Cogn 17: 693-701.

27. Loftus EF, Loftus GR, Messo J (1987) Some Facts about "Weapon Focus”. Law and Human Behavior 11: 55-62.

28. Arntz A, de Groot C, Kindt M (2005) Emotional memory is perceptual. J Behav Ther Exp Psychiatry 36: 19-34.

29. Christianson SA, Loftus E (1990) Some characteristics of people's traumatic memories. Bulletin of the Psychonomic Society 28: 195-198.

30. Safer MA, Christianson SA, Autry MW, Oesterlund K (1998) Tunnel Memory for Traumatic Events. Applied Cognitive Psychology 12: 99-117.

31. Rubin DC, Berntsen D, Bohni MK (2008) A memory-based model of posttraumatic stress disorder: evaluating basic assumptions underlying the PTSD diagnosis. Psychol Rev 115: 985-1011.

32. Layton B, Krikorian R (2002) Memory mechanisms in posttraumatic stress disorder. J Neuropsychiatry Clin Neurosci 14: 254-261.

33. Christianson SA (1992) Emotional stress and eyewitness memory: a critical review. Psychol Bull 112: 284-309.

34. Payne JD, Jackson ED, Ryan L, Hoscheidt S, Jacobs JW, et al. (2006) The impact of stress on neutral and emotional aspects of episodic memory. Memory 14: 1-16.

35. Schmidt SR (2004) Autobiographical memories for the September 11th attacks: reconstructive errors and emotional impairment of memory. Mem Cognit 32: 443-454.

36. Garcia-Moreno C, Jansen HA, Ellsberg M, Heise L, Watts CH; WHO Multi-country Study on Women's Health and Domestic Violence against Women Study Team (2006) Prevalence of intimate partner violence: findings from the WHO multi-country study on women's health and domestic violence. Lancet 368: 1260-1269.

37. Golding JM (1999) Intimate partner violence as a risk factor for mental disorders: A meta-analysis. Journal of Family Violence 14: 99-132.

38. Yang MS, Yang MJ, Chang SJ, Chen SC, Ko YC (2006) Intimate partner violence and minor psychiatric morbidity of aboriginal Taiwanese women. Public Health Rep 121: 453-459.

39. Hou WL, Wang HH, Chung HH (2005) Domestic violence against women in Taiwan: their life-threatening situations, post-traumatic responses, and psycho-physiological symptoms: an interview study. Int J Nurs Stud 42: 629-636.

40. Holmes EA, Brewin CR, Hennessy RG (2004) Trauma films, information processing, and intrusive memory development. J Exp Psychol Gen 133: 3-22.

41. Chou FH, Su TT, Ou-Yang WC, Chien IC, Lu MK, et al. (2003) Establishment of a disaster-related psychological screening test. Aust N Z J Psychiatry 37: 97-103.

42. Davidson JR, Book SW, Colket JT, Tupler LA, Roth S, et al. (1997) Assessment of a new self-rating scale for post-traumatic stress disorder. Psychological Medicine 27: 153-160.

43. Chen CH, Lin SK, Tang HS, Shen WW, Lu ML (2001) The Chinese version of the Davidson Trauma Scale: A practice test for validation. Psychiatry \& Clinical Neurosciences 55: 493-499.

44. Wechsler D (1997a) Wechsler adult intelligence scale-Third Edition (WAIS-III). San Antonio, Texas: Psychological Corporation.

45. Chen H Y, Hua MS, Zhu JJ (2007) Development of the Taiwan WAIS-III Two-Subtest Short Forms. Psychological Testing 54: 305-330.

46. Wechsler D (1997b) Wechsler Memory scale-Third Edition (WMS-III). San Antonio, Texas: Psychological Corporation.

47. Lezak MD (2004) Neuropsychological assessment. New York: Oxford University Press.Rey A (1964) L'examen clinique en psychologie. Paris:presses Universitaires de France.

48. Nelson HE (1976) A modified card sorting test sensitive to frontal lobe defects. Cortex 12: 313-324.
49. Beck AT, Steer RA, Brown GK (1996) Beck Depression inventory-Second Edition (BDI-II) manual. San Antonio, Texas: The Psychological Corporation.

50. Steer RA, Clark DA, Beck AT, Ranieri WF (1999) Common and specific dimensions of self-reported anxiety and depression: the BDI-II versus the BDI-IA. Behav Res Ther 37: 183-190.

51. Vasterling JJ, Verfaellie M (2009) Introduction-posttraumatic stress disorder: a neurocognitive perspective. J Int Neuropsychol Soc 15: 826-829.

52. Gilbertson MW, Gurvits TV, Lasko NB, Orr SP, Pitman RK (2001) Multivariate assessment of explicit memory function in combat veterans with posttraumatic stress disorder. J Trauma Stress 14: 413-432.

53. Jenkins MA, Langlais PJ, Delis D, Cohen R (1998) Learning and memory in rape victims with posttraumatic stress disorder. Am J Psychiatry 155: 278-279.

54. Vasterling JJ, Brailey K, Constans JI, Sutker PB (1998) Attention and memory dysfunction in posttraumatic stress disorder. Neuropsychology 12: $125-133$.

55. Eren-Koçak E, Kiliç C, Aydin I, Hizli FG (2009) Memory and prefrontal functions in earthquake survivors: differences between current and past post-traumatic stress disorder patients. Acta Psychiatr Scand 119: 35-44.

56. Kanagaratnam P, Asbjørnsen AE (2007) Executive deficits in chronic PTSD related to political violence. J Anxiety Disord 21: 510-525.

57. Stein MB, Kennedy CM, Twamley EW (2002) Neuropsychological function in female victims of intimate partner violence with and without posttraumatic stress disorder. Biol Psychiatry 52: 1079-1088.

58. Brewin CR, Kleiner JS, Vasterling JJ, Field AP (2007) Memory for emotionally neutral information in posttraumatic stress disorder: A meta-analytic investigation. J Abnorm Psychol 116: 448-463.

59. Isaac CL, Cushway D, Jones GV (2006) Is posttraumatic stress disorder associated with specific deficits in episodic memory? Clin Psychol Rev 26: 939-955.

60. Neylan TC, Lenoci M, Rothlind J, Metzler TJ, Schuff N, et al. (2004) Attention, learning, and memory in posttraumatic stress disorder. J Trauma Stress 17: 41-46.

61. Werner NS, Meindl T, Engel RR, Rosner R, Riedel M, et al. (2009) Hippocampal function during associative learning in patients with posttraumatic stress disorder. J Psychiatr Res 43: 309-318.

62. Burriss L, Ayers E, Ginsberg J, Powell DA (2008) Learning and memory impairment in PTSD: relationship to depression. Depress Anxiety 25: 149-157.

63. Pederson CL, Maurer SH, Kaminski PL, Zander KA, Peters CM, et al. (2004) Hippocampal Volume and Memory Performance in a Community-Based Sample of Women with Posttraumatic Stress Disorder Secondary to Child Abuse. Journal of Traumatic Stress 17: 37-40.

64. Dickie EW, Brunet A, Akerib V, Armony JL (2008) An fMRI investigation of memory encoding in PTSD: influence of symptom severity. Neuropsychologia 46: 1522-1531.

65. Squire LR, Zola SM (1997) Amnesia, memory and brain systems. Philos Trans R Soc Lond B Biol Sci 352: 1663-1673.

66. Kolb LC (1987) A neuropsychological hypothesis explaining posttraumatic stress disorders. Am J Psychiatry 144: 989-995.

67. Nagamine M, Matsuoka Y, Mori E, Fujimori M, Imoto S, et al. (2007) Short Communication: Relationship between heart rate and emotional memory in subjects with a past history of post-traumatic stress disorder. Psychiatry and Clinical Neurosciences 61: 441-443.

68. Orr SP, Roth WT (2000) Psychophysiological assessment: clinical applications for PTSD. J Affect Disord 61: 225-240.

69. Chan RC, Shum D, Toulopoulou T, Chen EY (2008) Assessment of executive functions: review of instruments and identification of critical issues. Arch Clin Neuropsychol 23: 201-216.

70. Golier J, Yehuda R (2002) Neuropsychological processes in posttraumatic stress disorder. Psychiatr Clin North Am 25: 295-315, vi. 
Citation: Chung SY, Tang SH, Shie JP, Tsai KY, Huang-Chih Chou F (2014) Emotional Memory and Posttraumatic Stress Disorder: A Preliminary Neuropsychological Study in Female Victims of Domestic Violence. J Psychiatry 17: 1000148. doi: $10.4172 / 2378-5756.1000148$

Page 9 of 9

71. Pacella ML, Irish L, Ostrowski SA, Sledjeski E, Ciesla JA, et al. (2011) Avoidant coping as a mediator between peritraumatic dissociation and posttraumatic stress disorder symptoms. J Trauma Stress 24: 317-325.

72. Birmes P, Brunet A, Carreras D, Ducassé JL, Charlet JP, et al. (2003) The predictive power of peritraumatic dissociation and acute stress symptoms for posttraumatic stress symptoms: a three-month prospective study. Am J Psychiatry 160: 1337-1339.

73. Shalev AY, Peri T, Canetti L, Schreiber S (1996) Predictors of PTSD in injured trauma survivors: a prospective study. Am J Psychiatry 153: 219-225.

74. American Psychiatric Association (2013) Diagnostic and Statistical Manual of Mental Disorders, 5th ed. (DSM-5). Washington, DC: American Psychiatric Press.

75. Karam EG, Andrews G, Bromet E, Petukhova M, Ruscio AM, et al.(2010) The role of criterion A2 in the DSM-IV diagnosis of posttraumatic stress disorder. Biol Psychiatry 68: 465-473.

76. Friedman MJ, Resick PA, Bryant RA, Brewin CR (2011) Considering PTSD for DSM-5. Depress Anxiety 28: 750-769.

77. Kaysen D, Pantalone DW, Chawla N, Lindgren KP, Clum GA, et al.(2008) Posttraumatic stress disorder, alcohol use, and physical health concerns. J Behav Med 31: 115-125.
78. Koso M, Hansen S (2006) Executive function and memory in posttraumatic stress disorder: a study of Bosnian war veterans. Eur Psychiatry 21: 167-173.

79. Vasterling JJ, Dikmen S (2012) Mild traumatic brain injury and posttraumatic stress disorder: clinical and conceptual complexities. J Int Neuropsychol Soc 18: 390-393.

80. Green BL, Goodman LA, Krupnick JL, Corcoran CB, Petty RM, et al (2000) Outcomes of single versus multiple trauma exposure in a screening sample. J Trauma Stress 13: 271-286.

81. Pico-Alfonso MA (2005) Psychological intimate partner violence: the major predictor of posttraumatic stress disorder in abused women. Neurosci Biobehav Rev 29: 181-193.

82. Mechanic MB (2004) Beyond PTSD: mental health consequences of violence against women: a response to Briere and Jordan. J Interpers Violence 19: 1283-1289.

83. Hoffman YS, Diamond GM, Lipsitz JD (2011) The challenge of estimating PTSD prevalence in the context of ongoing trauma: the example of Israel during the Second Intifada. J Anxiety Disord 25: 788-793.

84. Mc Hugh MC, Frieze IH (2006) Intimate partner violence: new directions. Violence and Exploitation against Women and Girls 1087 